\title{
Study on Mass Transfer within the Microchannel Reactor
}

\author{
Dan Li
}

School of Chemical Engineering and Technology, Xi'an Shiyou University, Xi'an, China hunter2011@foxmail.com

Keywords: Microchannel reactor, Gas, $\mathrm{NaOH}$ solution, $\mathrm{CO} 2$ absorption, Mass transfer coefficient

\begin{abstract}
Taking $\mathrm{CO}_{2}$ absorption as background, this paper makes a research on the experiments of $\mathrm{CO}_{2}$ absorption of the $\mathrm{NaOH}$ solution within microchannel reactor. By changing the concentration, superficial gas velocity and superficial liquid velocity of $\mathrm{NaOH}$ solution, their impact on the $\mathrm{CO}_{2}$ absorption rate is studied, and the results show that the overall mass transfer coefficient $K_{G} a$ increases when $\mathrm{NaOH}$ solution concentration increases. Under the same superficial liquid velocity, when superficial gas velocity increases, $K_{G} a$ also increases, and with the increase of superficial gas velocity, the increasing trend gradually slows down. At the same superficial gas velocity, with the increase of superficial liquid velocity, $K_{G} a$ also increase, and with the increase of superficial gas velocity, the increasing trend becomes faster.
\end{abstract}

\section{Experimental part}

The experimental device is shown in figure 1, the ratio of $\mathrm{N}_{2}$ and $\mathrm{CO}_{2}$ gas flow is adjusted to 1: 1 by the mass flow meter, and the mixed gas gets into a microchannel of the microchannel reactor. The $\mathrm{NaOH}$ solution is withdrawn from advection pump at $30{ }^{\circ} \mathrm{C}$ super-heated water bath, then it flows into another microchannel of the microchannel reactor. Two-phase of liquid and gas contact in the main microchannel for the gas absorption process, and finally enter the gas-liquid separator for gas-liquid separation. The inner diameter of the microchannel reactor used in this experiment is $0.5 \mathrm{~mm}$. After the gas separation, the export flow is measured by the bubble flowmeter. Absorbing liquid titrates nitric acid solution to determine the amount of $\mathrm{CO} 2$ absorption. This experiment uses double indicator method, three consecutive parallel tests of each experiment are made to get the average.

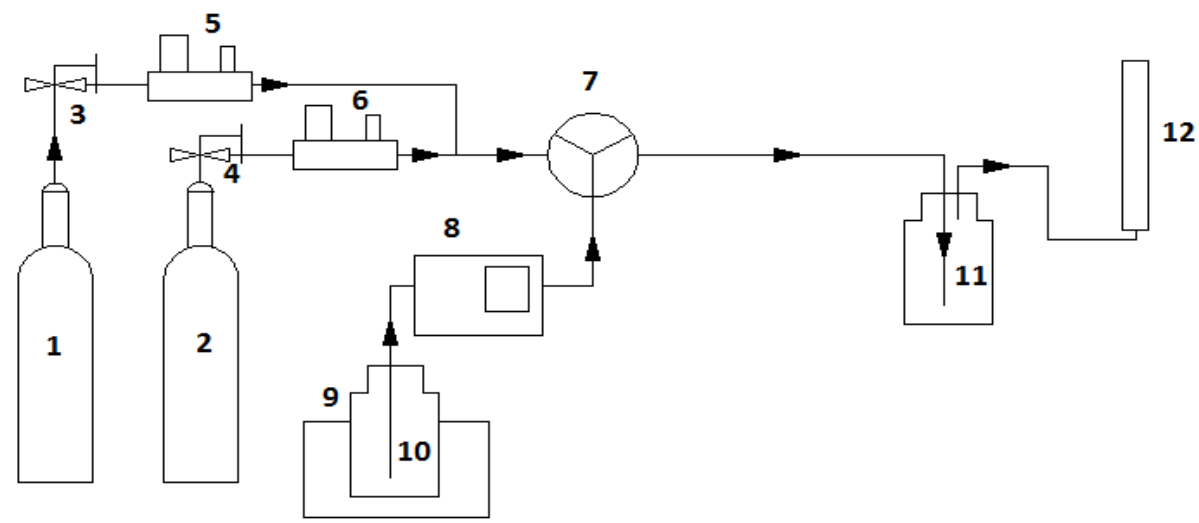

1- $\mathrm{N}_{2}$ cylinders 2- $\mathrm{CO}_{2}$ cylinders 3, 4-Valve 5,6-Gas mass flow meter 7-Microchannel reactor 8-Advection pump 9-Water bath 10,11-Jars 12-Bubble flowmeter

Fig.1Schematic representation of the experimental setup.

\section{Experimental principle}

The parameters during liquid mass transfer process such as gas-liquid volumetric mass transfer coefficient, the phase boundary area usually uses chemical absorption method to measure. As to the different actual situation for devices, we can select specific gas liquid reaction systems to 
characterize ${ }^{[1,2]}$. In order to increase the rate of mass transfer, this experiment adds $\mathrm{NaOH}$ into the water in order to increase the $\mathrm{CO}_{2}$ absorption rate in $\mathrm{N}_{2}$, and the reaction mechanism is as follows:

$$
\begin{aligned}
& \mathrm{CO}_{2}+\mathrm{OH}^{-} \rightarrow \mathrm{HCO}_{3}^{-} \\
& \mathrm{HCO}_{3}^{-}+\mathrm{OH}^{-} \rightarrow \mathrm{CO}_{3}^{2-}+\mathrm{H}_{2} \mathrm{O}
\end{aligned}
$$

In the above two formulas, (1) is irreversible secondary reaction, (2) is proton transfer reaction, the reaction rate constant in (2) is much bigger than that in (1), so (1) is the rate controlling step. Under the experimental conditions, the solution is alkaline, the equilibrium concentration of $\mathrm{HCO}_{3}^{-}$ can be ignored, so combine (1) and (2), the reaction is as follows:

$$
\mathrm{CO}_{2}+2 \mathrm{OH}^{-} \rightarrow \mathrm{CO}_{3}^{2-}+\mathrm{H}_{2} \mathrm{O}
$$

In this experimental system, the expression for the reaction rate equation is $r=k\left[\mathrm{CO}_{2}\right]\left[\mathrm{OH}^{-}\right], k$ is the reaction rate constant in alkaline, and its value can be calculated by the correlations Pohorecki ${ }^{[3]}$ put forward:

$$
\log _{10} k=11.916-\frac{2382}{T}+\sum b_{\text {ion }} I_{\text {ion }}
$$

Danckwert $^{[4-7]}$ developed that when alkali liquor absorbed $\mathrm{CO}_{2}$, if $\sqrt{10^{3} D_{A} k\left[O H^{-}\right]_{0}} / k_{L}^{0} \gg 1+C^{*} / 10^{3}\left[\mathrm{OH}^{-}\right]_{0}$, quasi-order reaction occurs, and the liquid mass transfer coefficient can be predicted by the following equation:

$$
\left(k_{L} a\right)^{2}=10^{3} a^{2} D_{A} k\left[O H^{-}\right]_{0}+\frac{4 a^{2} D_{A}}{\pi T}
$$

If $10^{3} k\left[\mathrm{OH}^{-}\right]_{0}>>\frac{4}{\pi T}$, the above equation can be simplified to:

$$
k_{L} a=a \sqrt{10^{3} D_{A} k\left[O H^{-}\right]_{0}}
$$

$D_{A}$ is the diffusion coefficient of solute in solution, which can be calculated by the correlations Versteeg ${ }^{[8,9]}$ put forward:

$$
D_{A}=D_{w, A}\left(1-1.29 \times 10^{-4}\left[\mathrm{OH}^{-}\right]\right), \quad D_{w, A}=2.35 \times 10^{-6} \exp \left(\frac{-2119}{T}\right)
$$

According to the relationship of gas phase total volume mass transfer coefficient, liquid volume mass transfer coefficient and gas volume mass transfer coefficient, the following equation can be obtained:

$$
\frac{1}{K_{G} a}=\frac{H}{k_{L} a}+\frac{1}{k_{G} a}
$$

Where, $\mathrm{H}$ is $\mathrm{CO}_{2}$ solubility in water, which can be calculated by the correlations Weisenberger ${ }^{[8,10]}$ put forward:

$$
H=10^{\sum h_{i}-h_{G}} / H_{w}, \quad h_{G}=h_{G, 0}+h_{T}(T-298.15), \quad H_{w}=3.54 \times 10^{-7} \exp (2044 / T)
$$

Substitute (6) into (7), we can get:

$$
\frac{1}{K_{G} a}=\frac{1}{a} \frac{H}{\sqrt{10^{3} D_{A} k\left[\mathrm{OH}^{-}\right]_{0}}}+\frac{1}{k_{G} a}
$$

$K_{G} a$ is total volume mass transfer coefficient, which is calculated by:

$$
K_{G} a=\frac{L \Delta x}{\left(y_{0}-y^{*}\right) P V}
$$

\section{Result and discussion}

Effect of liquid phase $\mathrm{NaOH}$ concentration on gas overall mass transfer constant. Fig. 2 shows the trend of gas overall mass transfer coefficient with $\mathrm{NaOH}$ concentration in liquid 
absorption within the microchannel reactor. As can be seen, under different concentrations of $\mathrm{NaOH}$ solution, $K_{G}$ is also different, and it increases with the increase of $\mathrm{NaOH}$ concentration. When the concentration of $\mathrm{NaOH}$ solution increases, the reaction rate will increase, thereby increasing the absorption rate. But with the increase of the $\mathrm{NaOH}$ solution concentration, the viscosity of the solution will increase correspondingly, which will make the diffusion coefficient of $\mathrm{CO}_{2}$ in the solution decrease so as to increase the liquid mass transfer resistance ${ }^{[11]}$. According to the experimental results obtained, we can see that the promoting role in a chemical reaction is much greater than the mass transfer resistance the concentration increase brought. As $\operatorname{Re}_{\mathrm{L}}$ increases, the liquid phase mass transfer coefficient and the phase boundary area also increase, thereby facilitating liquid transfer ${ }^{[11,12]}$. Therefore, the $\mathrm{Re}_{\mathrm{L}}$ increase has improved the capacity of gas-liquid two-phase mass transfer in microchannel reactor.

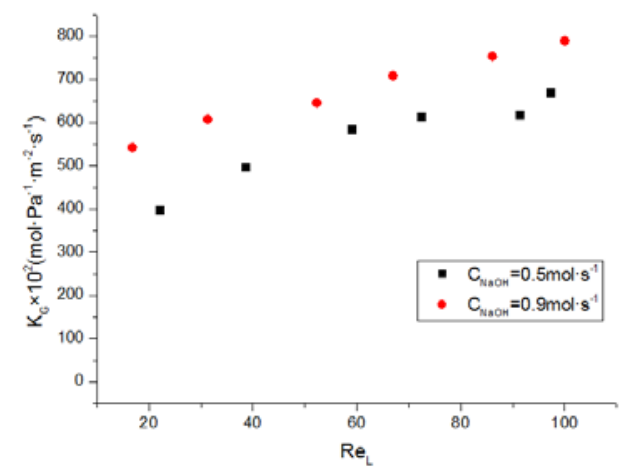

Fig.1.2 Effect of liquid phase $\mathrm{NaOH}$ concentration on $K_{G}$

Effect of superficial gas velocity on the overall mass transfer coefficient. Fig. 3 shows the effect of superficial gas velocity on overall mass transfer coefficient under different superficial liquid velocity when $\mathrm{NaOH}$ concentration is $0.5 \mathrm{~mol} / \mathrm{L}$. As it can be seen from the figure, when superficial liquid velocity remains unchanged, with the increase of superficial gas velocity, $K_{G} a$ also increases. The mass transfer coefficient trend is basically the same with the phenomenon a number of researchers observed within the microchannel when the equivalent diameter is greater than $1 \mathrm{~mm}{ }^{[13-15]}$. It can also be seen from the figure that the increasing trend of $K_{G} a$ is gradually slowing down with the increase of superficial gas velocity. This is because when the superficial gas velocity increases, the gas-liquid two-phase flow pattern will change from bomb-like flow to dispersed flow, and the change in the flow pattern will gradually slow the increasing trend of overall mass transfer coefficient.

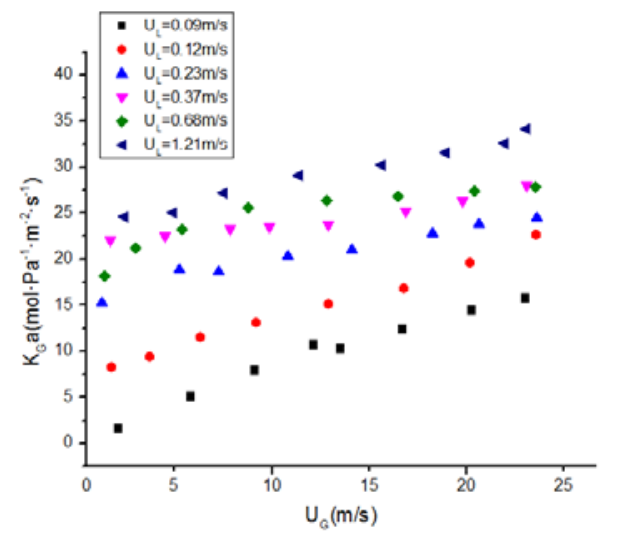

Fig. 3 Effect of superficial gas velocity on $K_{G} a$

Table 1 shows the mass transfer coefficient of the microchannel reactor and other conventional gas-liquid contactor the present study uses, which can be seen that the mass transfer coefficient of microchannel reactor is much bigger than that of traditional gas-liquid contactor. Microchannel has such a high mass transfer coefficient, which is particularly applicable for the multi-phase reaction whose controlling step is mass transfer ${ }^{[16]}$. Le Jun ${ }^{[17]}$ used a microchannel reactor with rectangular cross section and equivalent diameter of $667 \mu \mathrm{m}$, and he used $0.3 \mathrm{~mol} \cdot \mathrm{L}^{-1} \mathrm{NaHCO}_{3} / 0.3$ 
$\mathrm{mol} \cdot \mathrm{L}^{-1} \mathrm{NaCO}_{3}$ aqueous for absorption of CO2, with a total mass transfer coefficient of $21 \mathrm{~s}^{-1}$. Inoue ${ }^{[18]}$ used $\mathrm{H}_{2}$ and $\mathrm{O}_{2}$ to make hydrogen peroxide in the micro-packed bed reactor with the overall mass transfer coefficient up to $3.8 \mathrm{~s}^{-1}$.

Table 1 the comparison of mass transfer coefficients in different gas-liquid contactors

\begin{tabular}{cc}
\hline Reactor Type & $k_{L} a \times 10^{2}\left(\mathrm{~s}^{-1}\right)$ \\
\hline Bubble tower & $0.5-24$ \\
Packed tower, countercurrent & $0.04-7$ \\
Packed column, stream & $0.04-102$ \\
Spray tower & $1.5-2.2$ \\
Couette Taylor stream reactor & $3-21$ \\
Stirred tank & $3-40$ \\
Spray absorber & $2.5-122$ \\
Tubular reactor, vertical & $2-100$ \\
Tubular reactors, horizontal and hovering & $0.5-70$ \\
Static mixer & $10-250$ \\
Gas-liquid microchannel contactor & $30-2100$ \\
Microchannel in this experiment & $40-3400$
\end{tabular}

Effect of superficial liquid velocity on the overall mass transfer coefficient. Fig. 4 shows the effect of superficial liquid velocity on the overall mass transfer coefficient at different superficial gas velocity with $\mathrm{NaOH}$ concentration of $0.5 \mathrm{~mol} / \mathrm{L}$. As can be seen from the figure, the trend is similar to that of the mass transfer coefficient shown in Figure 3. At any kind of superficial gas velocity, the overall mass transfer coefficient will increase when superficial liquid velocity increases, but the increase trend is faster. The reason for this phenomenon is that the flow pattern makes change. When the superficial liquid velocity increases, the gas-liquid two-phase interfacial area increases, and film thickness increases, and flow pattern becomes turbulent, so when superficial liquid velocity increases, the increase trend of overall mass transfer coefficient has not slowed.

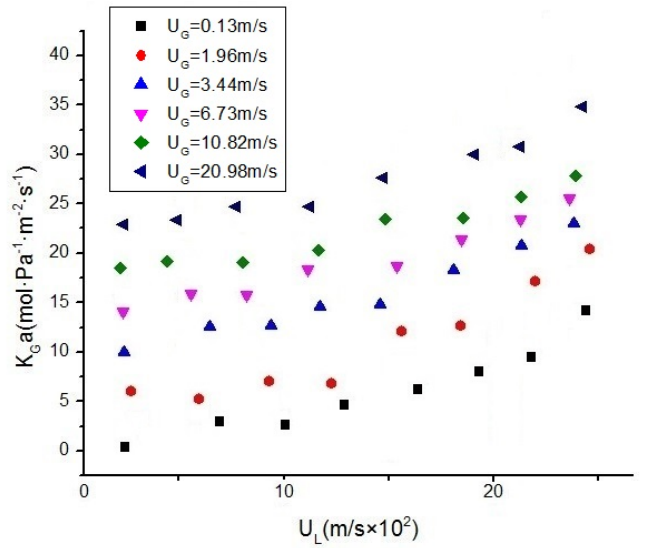

Fig. 4 Effect of superficial liquid velocity on $K_{G} a$

\section{Summary}

This paper examines the gas-liquid two-phase transfer characteristics in the circular microchannel with diameter of $0.5 \mathrm{~mm}$, which uses $\mathrm{NaOH}$ solution to absorb $\mathrm{CO}_{2}-\mathrm{N}_{2}$ mixture gas to measure the overall mass transfer coefficient, and then predict the gas-liquid two-phase mass transfer boundary area. The summary of this paper is as follows:

The gas overall mass transfer coefficient in microchannel reactor will increase when $\mathrm{NaOH}$ concentration increases, and the greater the gas phase is, the bigger the overall mass transfer coefficient is.

At the same superficial liquid velocity, the overall mass transfer coefficient also increases when 
superficial gas velocity increases, but the increase trend gradually slows down. This is because when the superficial gas velocity increases, the gas-liquid two-phase flow pattern will change from bomb-like flow to dispersed flow, and the degree reduction of film turbulence will cause the trend to slow down.

At the same superficial gas velocity, the overall mass transfer coefficient also increases when superficial liquid velocity increases, and the increase trend becomes faster with the increase of superficial gas velocity. This is because when the superficial liquid velocity increases, the gas-liquid two-phase flow pattern will not change basically, and the degree of film turbulence will be bigger and bigger.

\section{Symbol Description}

$a$-Boundary area, $\mathrm{m}^{2} / \mathrm{m}^{3}$

$b_{i o n}$ Contribution of each ion in formula (4), $\mathrm{m}^{3} / \mathrm{mol}$

$C^{*}$ _ Physical solubility of solute in the liquid phase, $\mathrm{mol} / \mathrm{m}^{3}$

$D_{A} \longrightarrow$ Solute diffusion coefficient in solution, $\mathrm{m}^{2} / \mathrm{s}$

$D_{w, A}-$ Solute diffusion coefficient in water, $\mathrm{m}^{2} / \mathrm{s}$

$h_{G} \longrightarrow$ Gas properties constant, $\mathrm{m}^{3} / \mathrm{kmol}$

$h_{T}$ _Gas specific parameters of temperature effect, $\mathrm{m}^{3} \cdot \mathrm{kmol}^{-1} \cdot \mathrm{K}^{-1}$

$H \longrightarrow$ Solubility of carbon dioxide in aqueous solution, $\mathrm{Pa} \cdot \mathrm{m}^{3} \cdot \mathrm{mol}^{-1}$

$H_{w} \longrightarrow$ Solubility of carbon dioxide in water, $\mathrm{mol} \cdot \mathrm{m}^{-3} \cdot \mathrm{Pa}^{-1}$

$k-$ Reaction rate constant in lye

$k_{G} a-$ Gas film mass transfer coefficient, $\mathrm{mol} \cdot \mathrm{Pa}^{-1} \cdot \mathrm{s}^{-1} \cdot \mathrm{m}^{-3}$

$K_{G} a-$ Overall mass transfer coefficient, $\mathrm{mol} \cdot \mathrm{Pa}^{-1} \cdot \mathrm{s}^{-1} \cdot \mathrm{m}^{-3}$

$k_{L} a-$ Liquid film mass transfer coefficient, $\mathrm{s}^{-1}$

$L$ Liquid flow rate, $\mathrm{mol} \cdot \mathrm{s}^{-1}$

$\left[\mathrm{CO}_{2}\right]-$ Concentration of carbon dioxide in solution, $\mathrm{mol} \cdot \mathrm{L}^{-1}$

$\left[\mathrm{OH}^{-}\right]_{0}$ Concentration of $\mathrm{OH}^{-1}$ in solution, $\mathrm{mol} \cdot \mathrm{L}^{-1}$

$\left[\mathrm{OH}^{-}\right]$—Primary concentration of $\mathrm{OH}^{-1}, \mathrm{~mol} \cdot \mathrm{L}^{-1}$

$P$ _

$T$ - Temperature, $\mathrm{K}$

$V$-Microchannel volume, $\mathrm{m}^{3}$

$\Delta x$ - Mole fraction changes of carbon dioxide in the liquid phase

$y_{0}-$ Mole fraction of carbon dioxide in the gas phase body

$y^{*}$ —Balance mole fraction of carbon dioxide in the gas phase

\section{References}

[1] Xiong R, Chung J N. An experimental study of the size effect on adiabatic gas-liquid two-phase flow patterns and void fraction in microchannels. Physics of Fluids (1994-present), 2007, 19(3): 033301.

[2] Akbar,M.K., Plummer, D.A., Ghiaasiaan,S.M., On gas-liquid two-phase flow regimes in microchannels. International Journal of Multiphase Flow,2003 (29): 855-865.

[3] Pohorecki R, Moniuk W. Kinetics of reaction between carbon-dioxide and hydroxyl ions in aqueous--electrolyte solutions. Chem. Eng. Sci., 1988, 43: 1677.

[4] Danckwerts PV. Gas absorption accompanied by chemical reaction. AIChE Journal 1955, 1:456-463. 
[5] Relim TR,Moll AJ,Babb AL. Unsteady state absorption of carbon dioxide by dilute sodium hydroxide solutions. AIChE Journal, 1963, 9 (6): 760—765.

[6] Nijsing RATO, Hendriksz RH, Kramers H. Absorption of C02 in jets and falling films of electrolyte solutions, with and without chemical reaction. Chemical Engineering Science, 1959, 10 (1-2): 88-104.

[7] Richards GM,Ratcliff GA, Danckwerts PV. Kinetics of C02 absorption-III First-order reaction in a packed column. Chemical Engineering Science, 1964, 19:325-328.

[8] Shi K. Mixed H2/Hळ approach of full order state observer design for satellite attitude control system//2015 27th Chinese Control and Decision Conference. 2015: 4513-4517.

[9] Ratcliff GA, Holdcroft JG. Diffusivities of gases in aqueous electrolyte solutions .Transactions of the Institution of Chemical Engineers and the Chemical Engineer, 1963, 41: 315-319.

[10]Weisenberger S, Schumpe A. Estimation of gas solubilities in salt solutions at temperatures from $273 \mathrm{~K}$ to $363 \mathrm{~K}$. AIChE Journal, 1996, 42 (1): 298-300.

[11]Zhang Haocui, Chen Guangwen, Yue Jun, Yuan Quan. Hydrodynamics and mass transfer of gas-liquid flow in a falling film mieroreactor. AjC E-, 2009, 55: 1110.

[12]Crause J C, Nieuwoudt I. Mass transfer in a short wetted wall column (I): Pure components. Industrial \& Engineering Chem istry Research, 1999, 38: 4928.

[13]Zhao, T.S., Bi, Q.C., Co-current air-water two-phase flow patterns in vertical triangular microchannels. International Journal of Multiphase Flow, 2001 (27):765-782.

[14] Yang, C.Y., Shieh, C.C., Flow pattern of air-water and two-phase R-134a in small circular tubes. International Journal of Multiphase Flow, 2001 (27):1163-1177.

[15]Chen, W.L., Twu, M.C., Pan. C., Gas-liquid two-phase flow in micro-channels. International Journal of Multiphase Flow, 2002 (28): 1235-1247.

[16]Niu H, Pan L, Wang S. Flow pattern and gas2liquid interfacial area in a microchannel contactor.Modern Chemical Industry, 2009, 29 (5): 60-64.

[17] Yue J, Chen G, Yuan Q, et al. Hydrodynamics and mass transfer characteristics in gas-liquid flow through a rectangular microchannel. Chemical Engineering Science, 2007, 62(7): 2096-2108. 